\title{
Five-year visual results of intravitreal bevacizumab in refractory inflammatory ocular neovascularization
}

This article was published in the following Dove Press journal:

Clinical Ophthalmology

31 July 2012

Number of times this article has been viewed

\author{
Ahmad M Mansour ${ }^{1,2}$ \\ Friederike Mackensen ${ }^{3}$ \\ Padmamalini Mahendradas ${ }^{4}$ \\ Moncef Khairallah ${ }^{5}$ \\ Timothy YY Lai ${ }^{6}$ \\ Ziad Bashshur' \\ 'Department of Ophthalmology, \\ American University of Beirut, \\ ${ }^{2}$ Rafic Hariri University Hospital, \\ Beirut, Lebanon; ${ }^{3}$ Interdisciplinary \\ Uveitis Center, University of \\ Heidelberg, Heidelberg, Germany; \\ ${ }^{4}$ Departments of Uveitis and \\ Retina, Narayana Nethralaya, \\ Bangalore, India; ${ }^{5}$ Department of \\ Ophthalmology, Fattouma Bourguiba \\ University Hospital, Monastir, Tunisia; \\ ${ }^{6}$ Department of Ophthalmology \\ and Visual Sciences, The Chinese \\ University of Hong Kong, Hong Kong \\ Eye Hospital, Kowloon, Hong Kong
}

Correspondence: Ahmad Mansour Department of Ophthalmology, American University of Beirut, PO Box II 3-6044, Beirut, Lebanon Tel +96| I 374625

Email ammansourmd@gmail.com
Purpose: To assess the 5-year visual outcome of intravitreal bevacizumab in inflammatory ocular neovascularization.

Methods: Retrospective, multicenter, consecutive case series of eight patients with inflammatory ocular neovascularization refractory to standard therapy who were treated with intravitreal bevacizumab and followed for 5 years after first injection. The outcome measures included improvement of best-corrected visual acuity expressed as logarithm of minimum angle of resolution.

Results: Mean best-corrected visual acuity significantly improved from 0.58 at baseline $(6 / 23$ or $20 / 76$; standard deviation $=0.32)$ to 0.20 at final assessment $(6 / 10$ or $20 / 32$; standard deviation $=0.25)(\mathrm{n}=8 ; P=0.02)$, a gain of 3.8 lines (median: three injections; eight eyes; eight patients). No ocular or systemic complications from intravitreal bevacizumab were noted.

Conclusion: At 5 years, intravitreal bevacizumab sustained significant visual improvement in ocular neovascularization due to a variety of inflammatory ocular diseases without major complications after a median of three injections.

Keywords: bevacizumab, choroidal neovascularization, punctate inner choroidopathy, toxoplasmosis, uveitis, Vogt-Koyanagi-Harada syndrome

\section{Introduction}

Uveitis-associated choroidal new vessel membranes (ie, choroidal neovascularization $[\mathrm{CNV}]$ ) are relatively rare complications of posterior segment inflammation, ${ }^{1-10}$ which mainly occur in multifocal choroiditis with panuveitis $(39 \%)$, punctate inner choroidopathy (29\%), serpiginous choroiditis (18\%), and Vogt-Koyanagi-Harada $(10 \%) .{ }^{1-24}$ The current standard of care involves control of uveitis in a stepladder fashion with oral, periocular, or intraocular corticosteroids, along with immunosuppressive therapies. ${ }^{11,12}$ When this medical therapy fails to cause CNV regression, additional interventions have been advocated, eg, argon laser photocoagulation, photodynamic therapy, and antivascular endothelial growth factor (anti-VEGF) drugs. ${ }^{1-24}$ The authors' study group has reported short-term (3 months), mid-term (6 months to 2 years), and 3 -year results of intravitreal bevacizumab in inflammatory $\mathrm{CNV}$, showing significant visual improvement and regression of ocular neovascularization in a wide variety of ocular diseases. ${ }^{10-12}$ The majority of studies analyzing the clinical efficacy of VEGF antagonists in uveitis or age-related macular degeneration or myopic CNV are short term (2 years or less). ${ }^{1-24}$ In the current study, the 5-year visual and anatomic outcomes of intravitreal bevacizumab in inflammatory neovascular disorders in a multicenter, retrospective, consecutive, nonrandomized, interventional study are analyzed. 


\section{Methods}

Eight consecutive cases of recalcitrant (failed standard therapy) $)^{11,12}$ inflammatory ocular neovascularization were treated with intravitreal bevacizumab and followed for 5 years ending March 2012. Intravitreal bevacizumab was injected using a 30-gauge needle in a sterile manner after topical anesthesia and povidone instillation in the lower cul-de-sac. The dosage of intravitreal injections varied initially between institutions, but the smaller dosage became uniform across the institutions later in the study. Injections were done according to monthly follow-up based on optical coherence tomography (OCT) and fluorescein angiography (FA). Patients were treated in a stepwise fashion with high doses of oral corticosteroid, with or without intraocular or periocular corticosteroid or immunosuppressive therapy as monitored by a rheumatologist. All patients signed an informed consent after being given information about the off-label usage of the drug.

Best-corrected visual acuity (BCVA) was assessed using either an Early Treatment Diabetic Retinopathy Study chart or Snellen chart and listed as logarithm of the minimal angle of resolution equivalents. Retreatment was done when there was recurrent activity evaluated by fundus examination, FA (leakage, growth of CNV), or OCT. Differences between final and initial BCVA were compared using paired Student's $t$-test, and a $P$ value less than 0.05 was considered significant. CNV size was determined by the early stages of FA (in disc diameters).

\section{Results}

Eight consecutive eyes of eight patients - one male and seven females, five Caucasians and three Asians, mean age 33 years (range 17-51 years) - were examined at baseline and followed up for 60 months (Table 1). The right eye was involved in four subjects and the left in four subjects. Uveitis was active in two eyes at the time of ocular neovascularization. Prior therapies to intravitreal bevacizumab included: oral corticosteroid (five eyes), subtenon corticosteroid (two eyes), intraocular corticosteroid (two eyes), and immunosuppressive agents (two patients). Additional multiroute corticosteroid therapies were administered with reactivation of the disease prior to intravitreal bevacizumab throughout the 5-year study period. In most cases, immunosuppression was maintained 6 months after both the primary disease and CNV became inactive clinically, or by FA and OCT. Immunosuppression consisted of mycophenolate mofetil, methotrexate, and azathioprine. The diagnosis was punctate inner choroidopathy (three eyes), Vogt-Koyanagi-Harada disease (two eyes), ocular toxoplasmosis (two eyes), and tuberculosis (one case).

Mean CNV size was 1.4 disc diameters (range 0.5-2 disc diameters). CNV was subfoveal in three eyes, juxtafoveal in five eyes, and peripapillary in two eyes. Mean BCVA improved from 0.58 at baseline $(6 / 23$ or $20 / 76$; standard deviation $=0.32)$ to 0.20 at final assessment $(6 / 10$ or $20 / 32$; standard deviation $=0.25)(\mathrm{n}=8 ; P=0.02$ using two-tailed two-sample unequal variance $t$-test), a gain of 3.8 lines. BCVA improved by one to three lines in three eyes,

Table I Five-year follow-up of intravitreal bevacizumab (Avastin ${ }^{\circledR}$ ) for inflammatory choroidal neovascularization

\begin{tabular}{|c|c|c|c|c|c|c|c|c|}
\hline $\begin{array}{l}\text { Numberl } \\
\text { age (years)/ } \\
\text { gender/race }\end{array}$ & Disease & $\begin{array}{l}\text { Duration } \\
\text { at initial } \\
\text { injection } \\
\text { of Avastin } \\
\text { (months) }\end{array}$ & $\begin{array}{l}\text { ODII } \\
\text { OS2 }\end{array}$ & $\begin{array}{l}\text { Initial vision } \\
\text { as logMAR }\end{array}$ & $\begin{array}{l}\text { Final vision } \\
\text { as logMAR }\end{array}$ & $\begin{array}{l}\text { Prior PO } \\
\text { steroid therapy } \\
(0=\text { no, I = yes })\end{array}$ & $\begin{array}{l}\text { Prior } \\
\text { subtenon } \\
\text { steroid } \\
\text { therapy }\end{array}$ & $\begin{array}{l}\text { Prior intraocular } \\
\text { steroid therapy } \\
\text { (0= no, } \\
\text { I = injection, } \\
2 \text { = dexamethasone } \\
\text { intravitreal implant) }\end{array}$ \\
\hline $\mathrm{I} / 26 / \mathrm{F} / \mathrm{C}$ & TX & 0.5 & 2 & 0.7 & 0.4 & 0 & 0 & 0 \\
\hline $2 / 30 / \mathrm{M} / \mathrm{A}$ & $\mathrm{TX}$ & 24 & 2 & 0.48 & 0.3 & I & 0 & 0 \\
\hline $3 / 44 / F / A$ & TB & I & I & 0.3 & 0 & I & 0 & 0 \\
\hline $4 / 5 \mathrm{I} / \mathrm{F} / \mathrm{C}$ & PIC & 2 & 2 & 0.7 & 0.7 & 0 & 0 & 0 \\
\hline $5 / 30 / F / A$ & PIC & I & I & 0.9 & 0.1 & 0 & 0 & 0 \\
\hline 6/40/F/C & PIC & 4 & I & 0.0 & 0.0 & I & 0 & I \\
\hline 7/29/F/C & VKH & 12 & I & I & 0 & I & I & 2 \\
\hline 8/I7/F/C & VKH & 96 & I & 0.54 & 0.1 & I & I & 0 \\
\hline
\end{tabular}


more than three lines in three eyes, and was stable in two eyes. There was a median of three injections (mean of five injections; range of one to 15 injections) during the study period. The OCT machines changed during the study in the same center and were different between centers, which precluded the investigators from analyzing the change in central foveal thickness after therapy (Table 1). No injection-related complications were recorded, and the posterior capsular cataract in two eyes was mild, did not require surgery, and resulted from either uveitis or corticosteroid intake.

\section{Discussion}

The natural history of subfoveal CNV in inflammatory ocular neovascularization is generally poor. ${ }^{25,26}$ Long-term results of photodynamic therapy in inflammatory ocular neovascularization appear to play a role in stabilizing vision. ${ }^{11}$ Intravitreal injections of VEGF inhibitors represent a specific treatment influencing the pathogenic pathway of $\mathrm{CNV}$ and retinal neovascularization. ${ }^{27-31}$ Excised inflammatory $\mathrm{CNV}$ overexpressed VEGF by immunohistochemistry, ${ }^{27,28,31}$ hence the importance of enhanced VEGF expression in the pathogenesis of inflammatory ocular neovascularization. Furthermore, blockage of VEGF has not been shown to have an antiinflammatory effect. ${ }^{32}$ Thus, treatment of the underlying inflammatory disease should play a central role in the management of uveitic $\mathrm{CNV}$ with the treatment regimen focusing on disease quiescence through the use of corticosteroids and immunosuppressive agents, while treating nonresponsive $\mathrm{CNV}$ with intravitreal anti-VEGF agents. ${ }^{32}$

Various large series of inflammatory neovascularization cases treated with VEGF antagonists have been published in the literature. Menezo et al noted visual stabilization or improvement in nine of ten patients with punctate inner choroidopathy treated with a mean of 1.9 injections of ranibizumab during an average follow-up of 1 year. ${ }^{21}$ Adan et al described nine patients with various inflammatory $\mathrm{CNV}$ treated with bevacizumab injections. ${ }^{13} \mathrm{CNV}$ resolved in all affected eyes with BCVA improving in $88.8 \%$ of eyes with mean follow-up of 7.1 months, and after a mean of 1.3 injections. Tran et al described ten patients with uveitic CNV followed for a mean of 7.5 months. ${ }^{9} \mathrm{CNV}$ was subfoveal in eight cases and juxtafoveal in two cases. After a mean number of 2.5 injections, logarithm of the minimal angle of resolution BCVA improved significantly from 0.62 (20/55) to $0.45(20 / 40)$ at 1 month, then remained stable during the follow-up. Lott et al treated 21 eyes with inflammatory ocular neovascularization and followed six eyes for 1 year with nonsignificant visual improvement from a median of $20 / 80$ (21 eyes) to $20 / 60$ (six eyes). ${ }^{20}$ Kramer et al treated ten patients with inflammatory ocular neovascularization with prompt intravitreal bevacizumab as the first-line therapy and found that in a majority of patients a single injection led to $\mathrm{CNV}$ resolution with long-term visual improvement. ${ }^{18}$

The current series has the longest follow-up of bevacizumab in ocular use and attests to the sustained

\begin{tabular}{|c|c|c|c|c|c|c|c|c|}
\hline $\begin{array}{l}\text { Prior } \\
\text { immunosuppressive } \\
\text { therapy }\end{array}$ & $\begin{array}{l}\text { Number of } \\
\text { bevacizumab } \\
\text { injections }\end{array}$ & $\begin{array}{l}\text { Location } \\
\text { of CNV } \\
\text { membrane }\end{array}$ & $\begin{array}{l}\text { Size of } \\
\text { CNV (DD) }\end{array}$ & $\begin{array}{l}\text { Uveitis at } \\
\text { time of } C N V \\
\text { (0= inactive, } \\
\text { I = active) }\end{array}$ & $\begin{array}{l}\text { Initial } \\
\text { foveal } \\
\text { thickness } \\
(\mu)\end{array}$ & $\begin{array}{l}\text { Final } \\
\text { foveal } \\
\text { thickness } \\
(\mu)\end{array}$ & $\begin{array}{l}\text { Avastin } \\
\text { dose (mL) }\end{array}$ & Complications \\
\hline
\end{tabular}

\begin{tabular}{|c|c|c|c|c|c|c|c|c|}
\hline 0 & 1 & Subfoveal & 1.5 & 0 & NA & 170 & 0.05 & No \\
\hline 0 & I & Subfoveal & 1.5 & 0 & 389 & 278 & 0.05 & No \\
\hline 0 & 3 & Juxtafoveal & 1.5 & 0 & 282 & 140 & 0.05 & PSC \\
\hline 0 & 3 & Juxtafoveal & NA & 0 & NA & NA & 0.1 then 0.05 & No \\
\hline 0 & 3 & Subfoveal & 0.5 & 0 & NA & NA & 0.05 & No \\
\hline 0 & 13 & Juxtafoveal & I & 0 & 230 & 196 & 0.1 then 0.05 & No \\
\hline I & 15 & $\begin{array}{l}\text { Juxtafoveal + } \\
\text { peripapillary }\end{array}$ & 2 & I & 244 & $202^{\#}$ & 0.1 then 0.05 & No \\
\hline I & I & $\begin{array}{l}\text { Juxtafoveal + } \\
\text { peripapillary }\end{array}$ & 2 & I & $\begin{array}{l}142 * \\
\text { (NA) }\end{array}$ & $\begin{array}{l}218 * * \\
\text { (NA) }\end{array}$ & 0.1 & PSC \\
\hline
\end{tabular}

Notes: *Just after injection; **during an episode of uveitis; \#different machines used at follow-up.

Abbreviations: A, Asian; C, Caucasian; CNV, choroidal neovascularization; DD, disc diameter; F, female; logMAR, logarithm of the minimum angle of resolution; M, male; NA, not assessable because of difference in optical coherence tomography machines between exams and/or value not available on the exact dates of initial treatment and 5 years after the first injection; OD, right eye; OS, left eye; PIC, punctate inner choroidopathy; PO, per os; PSC, posterior subcapsular cataract; TB, tuberculosis; TX, toxoplasmosis; VKH, Vogt-Koyanagi-Harada syndrome. 
positive effect of intravitreal bevacizumab on visual function in inflammatory ocular neovascularization. The drawbacks of the current study include the small size, the retrospective nature, and absence of a standard protocol for follow-up and treatment. A possible drawback is the conversion from Snellen to logarithm of the minimal angle of resolution. However, according to Kaiser, for patients with good visual acuity $(>20 / 50)$, the difference between the Snellen and Early Treatment Diabetic Retinopathy Study charts was less than one line, with similar results for intermediate vision. ${ }^{33}$ A large discrepancy existed for poor-vision eyes, which did not occur in the current study population. Nonetheless, the current study provides good evidence that intravitreal bevacizumab is an effective and safe therapy in the treatment of inflammatory CNV.

\section{Disclosures}

The authors report no conflicts of interest in this work. Institutional Review Board approval of the research was obtained from the American University of Beirut. The study was registered in the National Clinical Trials (NCT00645697).

\section{References}

1. Akesbi J, Brousseaud FX, Adam R, Rodallec T, Nordmann JP. Intravitreal bevacizumab (Avastin) in idiopathic retinitis, vasculitis, aneurysms and neuroretinitis. Acta Ophthalmol. 2010;88(2):40-41.

2. Ben Yahia S, Herbort CP, Jenzeri S, et al. Intravitreal bevacizumab (Avastin) as primary and rescue treatment for choroidal neovascularization secondary to ocular toxoplasmosis. Int Ophthalmol. 2008;28(4):311-316.

3. Chan WM, Lai TY, Liu DT, Lam DS. Intravitreal bevacizumab (avastin) for choroidal neovascularization secondary to central serous chorioretinopathy, secondary to punctate inner choroidopathy, or of idiopathic origin. Am J Ophthalmol. 2007;143(6):977-983.

4. Guthoff R, Goebel W. Intravitreal bevacizumab for choroidal neovascularization in toxoplasmosis. Acta Ophthalmol. 2009;87(6):688-690.

5. Julian K, Terrada C, Fardeau C, et al. Intravitreal bevacizumab as first local treatment for uveitis-related choroidal neovascularization: longterm results. Acta Ophthalmol. 2011;89(2):179-184.

6. Kucukerdonmez C, Akova YA, Yilmaz G. Intravitreal injection of bevacizumab in Eales disease. Ocul Immunol Inflamm. 2008;16(1): 63-65.

7. Kurup S, Lew J, Byrnes G, Yeh S, Nussenblatt R, Levy-Clarke G. Therapeutic efficacy of intravitreal bevacizumab on posterior uveitis complicated by neovascularization. Acta Ophthalmol. 2009;87(3):349-352.

8. Raffa L, Bawazeer A. Intravitreal bevacizumab injection in a 14-yearold Vogt-Koyanagi-Harada patient with choroidal neovascular membrane. Can J Ophthalmol. 2009;44(5):615-616.

9. Tran TH, Fardeau C, Terrada C, et al. Intravitreal bevacizumab for refractory choroidal neovascularization (CNV) secondary to uveitis. Graefes Arch Clin Exp Ophthalmol. 2008;246(12):1685-1692.

10. Mansour AM, Arevalo JF, Fardeau C, et al. Three-year visual and anatomic results of administrating intravitreal bevacizumab in inflammatory ocular neovascularization. Can J Ophthalmol. 2012;47(3):269-274.

11. Mansour AM, Arevalo JF, Ziemssen F, et al. Long-term visual outcomes of intravitreal bevacizumab in inflammatory ocular neovascularization. Am J Ophthalmol. 2009;148(2):310-316.
12. Mansour AM, Mackensen F, Arevalo JF, et al. Intravitreal bevacizumab in inflammatory ocular neovascularization. Am J Ophthalmol. 2008; 146(3):410-416.

13. Adan A, Mateo C, Navarro R, et al. Intravitreal bevacizumab (avastin) injection as primary treatment of inflammatory choroidal neovascularization. Retina. 2007;27(9):1180-1186.

14. Benevento JD, Jager RD, Noble AG, et al. Toxoplasmosis-associated neovascular lesions treated successfully with ranibizumab and antiparasitic therapy. Arch Ophthalmol. 2008;126(8):1152-1156.

15. Doctor PP, Bhat P, Sayed R, Foster CS. Intravitreal bevacizumab for uveitic choroidal neovascularization. Ocul Immunol Inflamm. 2009; 17(2):118-126

16. Ehrlich R, Ciulla TA, Maturi R, et al. Intravitreal bevacizumab for choroidal neovascularization secondary to presumed ocular histoplasmosis syndrome. Retina. 2009;29(10):1418-1423.

17. Fine HF, Zhitomirsky I, Freund KB, et al. Bevacizumab (avastin) and ranibizumab (lucentis) for choroidal neovascularization in multifocal choroiditis. Retina. 2009;29(1):8-12.

18. Kramer M, Axer-Siegel R, JaouniI T, et al. Bevacizumab for choroidal neovascularization related to inflammatory diseases. Retina. 2010;30(6): 938-944.

19. Kumar A, Sinha S. Rapid regression of disc and retinal neovascularization in a case of Eales disease after intravitreal bevacizumab. Can $J$ Ophthalmol. 2007;42(2):335-336.

20. Lott MN, Schiffman JC, Davis JL. Bevacizumab in inflammatory eye disease. Am J Ophthalmol. 2009;148(5):711-717.

21. Menezo V, Cuthbertson F, Downes SM. Positive response to intravitreal ranibizumab in the treatment of choroidal neovascularization secondary to punctate inner choroidopathy. Retina. 2010;30(9):1400-1404.

22. Rouvas A, Petrou P, Douvali M, et al. Intravitreal ranibizumab for the treatment of inflammatory choroidal neovascularization. Retina. 2011; 31(5):871-879.

23. Schadlu R, Blinder KJ, Shah GK, et al. Intravitreal bevacizumab for choroidal neovascularization in ocular histoplasmosis. Am $J$ Ophthalmol. 2008;145(5):875-878.

24. Vossmerbaeumer U, Spandau UH, Baltz S, Wickenhaeuser A, Jonas JB. Intravitreal bevacizumab for choroidal neovascularization secondary to punctate inner choroidopathy. Clin Experiment Ophthalmol. 2008; 36(3):292-294.

25. Kleiner RC, Ratner CM, Enger C, Fine SL. Subfoveal neovascularization in the ocular histoplasmosis syndrome. A natural history study. Retina. 1988;8(4):225-229.

26. Brown J Jr, Folk JC, Reddy CV, Kimura AE. Visual prognosis of multifocal choroiditis, punctate inner choroidopathy, and the diffuse subretinal fibrosis syndrome. Ophthalmology. 1996;103(7): $1100-1105$

27. Perentes Y, Chan CC, Bovey E, Uffer S, Herbort CP. Massive vascular endothelium growth factor (VEGF) expression in Eales' disease. Klin Monbl Augenheilkd. 2002;219(4):311-314.

28. Guerin E, Sheridan C, Assheton D, et al. SDF1-alpha is associated with VEGFR-2 in human choroidal neovascularisation. Microvasc Res. 2008; 75(3):302-307.

29. Maruotti N, Cantatore FP, Nico B, Vacca A, Ribatti D. Angiogenesis in vasculitides. Clin Exp Rheumatol. 2008;26(3):476-483.

30. Murugeswari P, Shukla D, Rajendran A, Kim R, Namperumalsamy P, Muthukkaruppan V. Proinflammatory cytokines and angiogenic and anti-angiogenic factors in vitreous of patients with proliferative diabetic retinopathy and Eales' disease. Retina. 2008;28(6):817-824.

31. Shimada H, Yuzawa M, Hirose T, Nakashizuka H, Hattori T, Kazato Y. Pathological findings of multifocal choroiditis with panuveitis and punctate inner choroidopathy. Jpn J Ophthalmol. 2008;52(4):282-288.

32. Gulati N, Forooghian F, Lieberman R, Jabs DA. Vascular endothelial growth factor inhibition in uveitis: a systematic review. Br JOphthalmol. 2011;95(2):162-165.

33. Kaiser PK. Prospective evaluation of visual acuity assessment: a comparison of Snellen versus ETDRS charts in clinical practice (an AOS thesis). Trans Am Ophthalmol Soc. 2009;107:311-324. 
Clinical Ophthalmology

\section{Publish your work in this journal}

Clinical Ophthalmology is an international, peer-reviewed journal covering all subspecialties within ophthalmology. Key topics include: Optometry; Visual science; Pharmacology and drug therapy in eye diseases; Basic Sciences; Primary and Secondary eye care; Patien Safety and Quality of Care Improvements. This journal is indexed on

PubMed Central and CAS, and is the official journal of The Society of Clinical Ophthalmology (SCO). The manuscript management system is completely online and includes a very quick and fair peer-review system, which is all easy to use. Visit http://www.dovepress.com/ testimonials.php to read real quotes from published authors. 